\title{
INTRA-ARTICULAR FLUID PRESSURE AND PAIN IN OSTEOARTHRITIS OF THE HIP
}

\author{
N. J. GODDARD, P. T. GOSLING
}

From St Bartholomew's Hospital, London

\begin{abstract}
We investigated the relationship between the pain experienced by 50 patients with osteoarthritis of the hip and the resting intra-articular pressure of the synovial fluid. We found a significant linear correlation between these factors, greater pain being experienced by patients with higher pressures. In 20 cases we showed that the pressure rises in extension and medial rotation and is least in flexion and mid-abduction.

These results help to explain the benefits of rotation osteotomy of the hip and of psoas release. They also help explain the natural resting position of the hip in patients with an acute effusion and the fixed deformities associated with late osteoarthritis of the hip.
\end{abstract}

It is generally accepted that a tense effusion in a joint is painful, and that aspiration is accompanied by relief of the pain. Our hypothesis was that the degree of pain experienced by patients with osteoarthritis of the hip was related to the pressure of any joint effusion.

The relationship between the degree of pain and the clinical and radiological features in osteoarthritis of the hip is unpredictable, but it is likely that a tense effusion would cause pain. Studies on experimental animals (Tachdjian and Grana 1968), and in patients with intracapsular hip fractures (Soto-Hall, Johnson and Johnson 1964), have shown that the intra-articular pressure rises in extension and in medial rotation. These movements are the first to be lost in the early stages of osteoarthritis, but may be restored to a certain extent by either general or regional anaesthesia. This suggests that loss of movement may be due to reflex inhibition rather than capsular contracture.

\section{MATERIAL AND METHODS}

During an eight-month period, 50 consecutive patients undergoing total hip arthroplasty, or any procedure which entailed opening the capsule of the hip had the following assessments:

N. J. Goddard, FRCS, Senior Orthopaedic Registrar

Royal National Orthopaedic Hospital, Brockley Hill, Stanmore, Middlesex HA7 4LP, England.

P. T. Gosling, MSc, Senior Physicist

Department of Medical Electronics, St Bartholomew's Hospital, West Smithfield, London ECl 7BE, England.

Requests for reprints should be sent to Mr N. J. Goddard.

(C) 1988 British Editorial Society of Bone and Joint Surgery $0301-620 \mathrm{X} / 88 / 1019 \$ 2.00$

J Bone Joint Surg [Br] 1988;70-B:52-5
1. Severity of pain before operation, as determined by a linear analogue scale, zero representing no pain and 10 the worst imaginable pain.

2. Pre-operative range of movement.

3. Range of movement after induction of anaesthesia.

4. Resting intra-articular pressure.

5. Changes in the intra-articular pressure produced by passive movement of the joint (first 20 cases only).

The intra-articular pressure was measured during the operation using a closed sterile system. Immediately before the capsule was incised a 23 gauge needle was inserted into the inferior aspect of the hip joint and connected via arterial pressure tubing to an external pressure transducer (Transamerica Delavel Type 4-327I). Care was taken to ensure that there were no air bubbles in the saline-filled tube, and that no fluid was introduced into the joint through the measurement system.

In the first 10 cases, pressures were recorded on an Elema-Schonander Type 34 Mingograph recorder with a Type 311 pressure amplifier, but after this we used a purpose-built, battery-powered pressure amplifier with an integral digital display (Department of Medical Electronics, St Bartholomew's Hospital). The zeropressure reference point was taken as the mid-capsular level and was set by eye (estimated error $\pm 2 \mathrm{~cm} \mathrm{H}_{2} \mathrm{O}$ ). The system was calibrated against a water column with a calibration accuracy of $0.5 \mathrm{~cm} \mathrm{H}_{2} \mathrm{O}$, which added to the zero error gave an estimated error of $\pm 2.5 \mathrm{~cm} \mathrm{H}_{2} \mathrm{O}$. After measurement of pressures, the needle was withdrawn, the capsule excised and the operation continued. The measurements added only about five minutes to an operation lasting from 1.5 to 2 hours.

This technique has been used in 50 hips, 47 in patients having total replacement, two during percutaneous aspiration of the joint, and one patient undergoing exploration for septic arthritis. There were 18 men and 


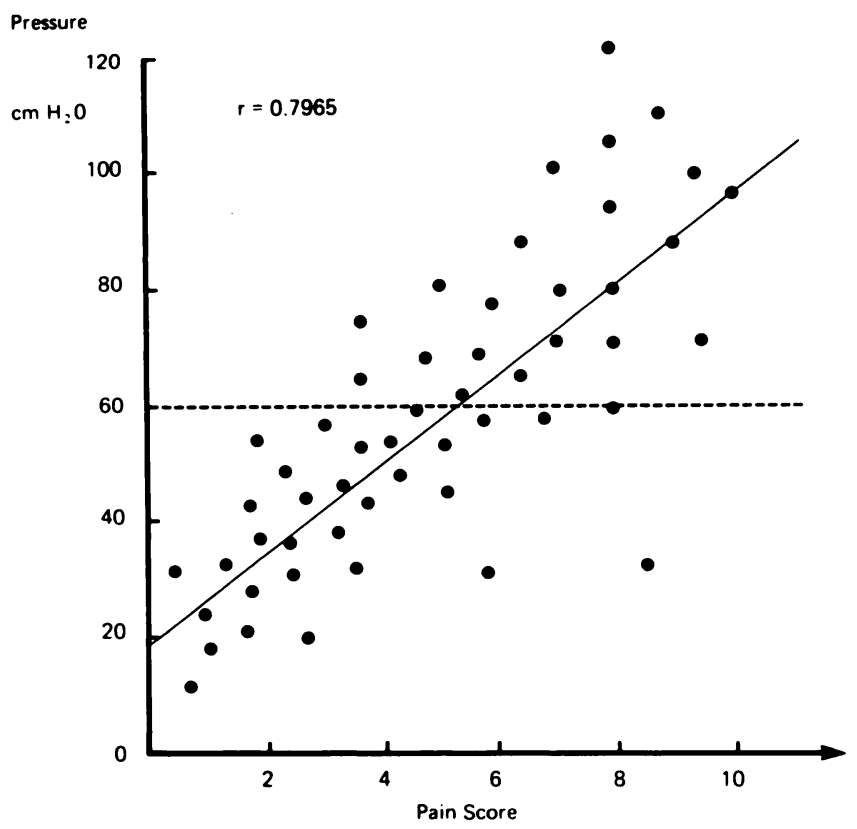

Fig. 1

To show the relationship between pain score and intra-articular pressure in 50 hips: the dashed line demarcates those with pressures above and below $60 \mathrm{~cm} \mathrm{H_{2 }} \mathrm{O}$ (see text).

32 women with a mean age of 70 years ( 32 to 89 ). Of the patients undergoing hip replacement, 38 had osteoarthritis, and nine had rheumatoid disease.

\section{RESULTS}

The relationship between pain and resting intra-articular pressure is shown in Figure 1. There is a good linear correlation $(r=0.796)$, more pain having been experienced by those patients with a higher resting pressure.

The two patients who had percutaneous aspiration of the hip provided an opportunity of relating pain and pressure before and after this procedure.

In the first case the pain score of nine associated

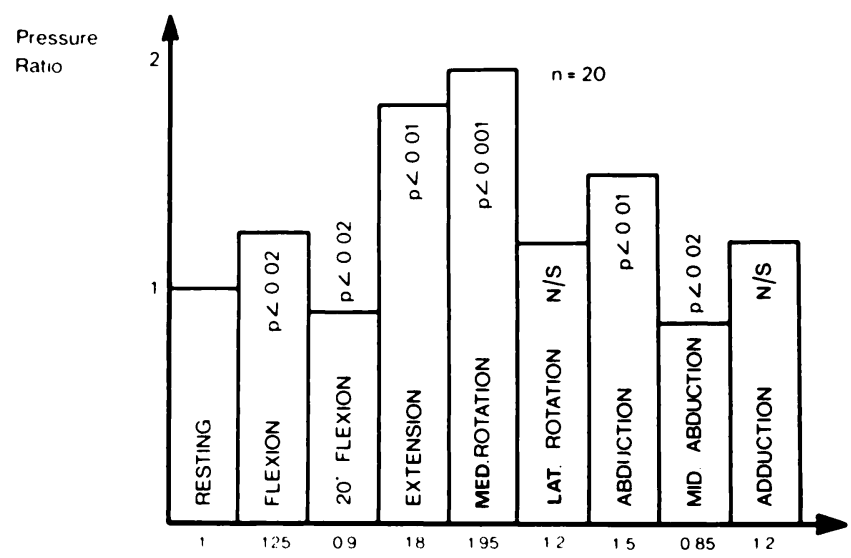

Fig. 2

To show the mean ratio of the resting pressure in 20 hips in a variety of positions. with a pre-aspiration pressure of $110 \mathrm{~cm} \mathrm{H} \mathrm{H}_{2} \mathrm{O}$ was reduced to three when pressure was $20 \mathrm{~cm} \mathrm{H}_{2} \mathrm{O}$. In the second case a pain score of eight at $105 \mathrm{~cm} \mathrm{H}_{2} \mathrm{O}$ became a score of two at $25 \mathrm{~cm} \mathrm{H}_{2} \mathrm{O}$. These results were not statistically significant but clearly suggest a relationship between pain and pressure. In both cases the volume of fluid aspirated was small ( 2 to $3 \mathrm{ml}$ ), and the position of the needle had been checked radiographically.

In the first 20 patients we recorded any change in pressure with movement of the joint. With the needle in situ, the pressures at the extremes of hip movement, however limited, were recorded. These pressures were expressed as a ratio of the resting pressure to eliminate the variation between resting values (Fig. 2).

This shows that the pressure increased almost twofold in medial rotation and in extension, and that it decreased slightly in mid-abduction and at about $20^{\circ}$ of flexion. This is relevant since medial rotation and

Table I. Results grouped according to resting intra-articular pressure

\begin{tabular}{|c|c|c|c|}
\hline & \multicolumn{2}{|c|}{ Intra-articular pressure } & \multirow[b]{2}{*}{$\begin{array}{l}\text { Significance of } \\
\text { difference }\end{array}$} \\
\hline & $\underset{(n=30)}{<60 \mathrm{~cm} \mathrm{H}_{2} \mathrm{O}}$ & $\begin{array}{l}>60 \mathrm{~cm}_{\left(n=22^{*}\right)} \mathrm{H}_{2} \mathrm{O} \\
.\end{array}$ & \\
\hline $\begin{array}{l}\text { Movements in degrees } \\
\text { Pre-operative } \\
\text { Under anaesthesia }\end{array}$ & $\begin{array}{r}83 \\
108\end{array}$ & $\begin{array}{l}111 \\
165\end{array}$ & $\begin{array}{l}\mathrm{p}<0.01 \\
\mathrm{p}<0.001\end{array}$ \\
\hline Pain score & $\begin{array}{c}3.3 \\
\text { (s.d. 2.2) }\end{array}$ & $\begin{array}{l}\quad 6.8 \\
\text { (s.d. 1.8) }\end{array}$ & $\mathrm{p}<0.001$ \\
\hline Age in years & 74 & 64 & $0.01>p>0.001$ \\
\hline
\end{tabular}

- Two patients had repeated examination 
extension are the movements which are lost first in the early stages of arthritis, and a position of abduction and slight flexion is that in which the hip comes to lie in cases of an acute effusion or septic arthritis.

The effect of pain (and pressure) on movement was studied in the whole group. The mean total range of movement before operation, expressed as the sum of the arcs of movement, was $95^{\circ}$. After induction of anaesthesia, this increased to $132^{\circ}$, the movements of extension and medial rotation in particular being restored.

When results are grouped as being above or below $60 \mathrm{~cm} \mathrm{H} \mathrm{H}_{2} \mathrm{O}$ resting pressure (near the mean value, $58.75 \mathrm{~cm} \mathrm{H}_{2} \mathrm{O}$ ), there are interesting differences, not only with regard to pain, but also in relation to range of movement and age (Table I).

Patients with a high resting pressure had a higher pain score, and also showed a greater increase in range of movement under anaesthesia.

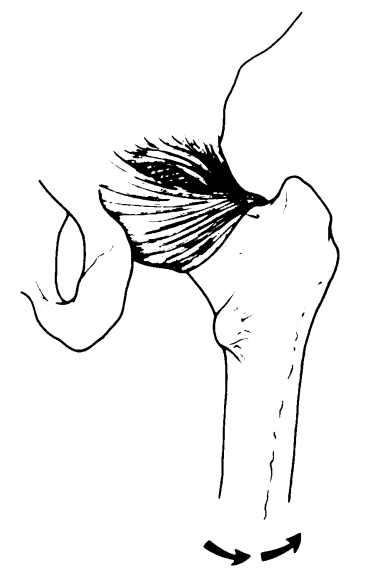

(1918) concerning the activity of tuberculous disease of the hip.

Soto-Hall et al. (1964) examined patients with intracapsular fractures of the femoral neck and found that the intra-articular pressure was lowest in slight flexion and lateral rotation and highest in medial rotation and extension. Two patients with a painful effusion had high resting pressures (68 and $78 \mathrm{~mm} \mathrm{Hg}$ ), and a study in two cadavers showed that psoas tenotomy almost halved the intra-articular pressure.

Eyring and Murray (1964) also studied the effect of joint position on the intra-articular pressure in a variety of joints; in the hip, the least pressure was at $30^{\circ}$ to $65^{\circ}$ of flexion, $15^{\circ}$ of abduction and $15^{\circ}$ of lateral rotation. Medial rotation, extension and wide abduction all increased the pressure. They injected the hips of six normal volunteers with sterile saline and, though they gave no figures, noted that an increase in the intra-

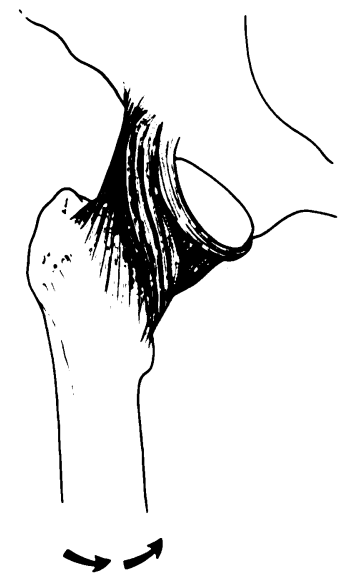

Fig. 3

Posterior and anterior views of a right hip to confirm that extension and medial rotation tend to tighten the capsule.

\section{DISCUSSION}

Both Walmsley (1928) and Lloyd-Roberts (1953) have discussed the role of the capsule in osteoarthritis of the hip and showed that, because of the spiral arrangement of its fibres, it became taut only in medial rotation and extension (Fig. 3). Walmsley also noted that the position of greatest relaxation was one of slight flexion combined with lateral rotation. It was in this position that the potential volume of the hip joint was greatest.

Although bony deformity and capsule contracture must contribute to the development of fixed deformities, Lloyd-Roberts (1953) felt that muscle spasm was the dominant feature. He concluded that pain and spasm both arose from stimulation of the richly innervated capsule (Gardner 1948). We believe that capsular pain results from stimulation of stretch receptors and that the subsequent spasm is a protective reflex. Similar observations formed the basis of the sign described by Gauvain articular pressure resulted in pain and that aspiration of the fluid gave instant relief.

Arnoldi, Lemperg and Linderholm $(1971,1975)$ and Lemperg and Arnoldi (1978) determined the relationship between painful osteoarthritis and a high resting intraosseous venous pressure and the reduction in this pressure which followed intertrochanteric osteotomy and cortical fenestration. They suggested that the high intraosseous venous pressure resulted from the blockage of flow in the peri-articular veins, so that the haemodynamic changes in the bone marrow were secondary to high pressure within the hip capsule. There was a linear correlation between the two (Arnoldi et al. 1979).

Our results suggest that the degree of pain experienced by patients with osteoarthritis of the hip is due in part to the direct effect of raised intra-articular pressure, rather than to the secondary effect of intra-osseous venous stasis. 
Conclusions. This work has enabled us to confirm that the hip joint behaves like most large joints in that the presence of a tense effusion leads to pain and the higher the resting pressure, the more the pain. It also suggests that osteoarthritis of the hip may present in one of two ways, depending upon the resting pressure. A high resting pressure is found in younger patients with a more mobile and more painful hip. A lower resting pressure tends to be found in an older patient, with a stiffer and less painful joint. The latter type may, of course, be merely the end-stage of the "high pressure" presentation.

Our results also help to explain the transient benefits of psoas release by tenotomy or osteotomy of the lesser trochanter and of intertrochanteric osteotomy. Psoas release decompresses the capsule while an intertrochanteric osteotomy allows the proximal femur to adopt a position of lateral rotation with slight abduction and flexion, which is the position with least pressure.

I wish to thank Mr A. W. F. Lettin, Mr J. A. Fixsen, Mr T. M. Bucknill and Mr J.P. Browett for allowing me to study their patients; thanks are due also to the Department of Medical Illustration at St Bartholomew's Hospital.

\section{REFERENCES}

Amoldi CC, Lemperg RK, Linderholm H. Immediate effect of osteotomy on the intramedullary pressure of the femoral head and neck in patients with degenerative osteoarthritis. Acta Orthop Scand $1971 ; 42: 357-65$.

Amoldi CC, Lemperg RK, Linderholm H. Intraosseous hypertension and pain in the knee. J Bone Joint Surg [Br] 1975;57-B:360-3.

Amoldi CC, Reimann I, Christensen SB, Mortensen S. The effect of increased intra-articular pressure on juxta-articular bone marrow pressure. IRCS Med Sci 1979;7:471.

Eyring EJ, Murray WR. The effect of joint position on the pressure of intra-articular effusion. J Bone Joint Surg [Am] 1964: 46-A : $1235-41$.

Gardner E. Innervation of hip joint. Anat Rec 1948:101:353-71.

Gauvain HJ. Tuberculous disease of the hip-joint : a sign of pathological activity. Lancet 1918;ii:666.

Lemperg RK, Amoldi CC. The significance of intraosseous pressure in normal and diseased states with special reference to the intraosseous engorgement-pain syndrome. Clin Orthop $1978 ; 1361-56$

Lloyd-Roberts GC. The role of capsular changes in osteoarthritis of the hip joint. J Bone Joint Surg [Br] 1953;35-B:627-42.

Soto-Hall R, Johnson LH, Johnson RA. Variations in the intra-articular pressure of the hip joint in injury and disease. J Bone Joint Surg [Br] 1964;46-A :509-16.

Tachdjian MO, Grana L. Response of the hip joint to increased intraarticular hydrostatic pressure. Clin Orthop 1968;61:199-212.

Walmsley T. The articular mechanism of the diarthroses. J Bone Joint Surg $1928 ; 10: 40-5$. 